\title{
PEMBERDAYAAN MASYARAKAT HIMPUNAN PENDUDUK PENGGUNA AIR MINUM (HIPPAM) DI DESA BALONGDOWO DAN DESA PUTAT, SIDOARJO, JAWA TIMUR
}

\author{
Farida Hardaningrum, S.Si, MT \\ Wiwin Agus Kristiana, S.T, M.T \\ Ani Wulandari S.S., MM \\ Universitas Narotama Surabaya, Jl. Arif Rahman Hakim 51, Telp. 0315946404 \\ Disampaikan pada Lokakarya dan Seminar Pengabdian kepada Masyarakat, \\ Kampus C Universitas Airlangga, 19 Oktober 2018
}

\begin{abstract}
RINGKASAN
Permasalahan sumber daya air terjadi di wilayah Kabupaten Sidoarjo. Banyaknya industri dan indikasi terjadinya intrusi air laut di berbagai daerah membuat Kabupaten Sidoarjo mengalami ancaman permasalahan air bersih yang cukup serius. Untuk itu pemerintah berupaya membentuk komunitas yaitu Himpunan Penduduk Pengguna Air Minum (HIPPAM) yang merupakan wadah bagi masyarakat dalam upaya meningkatkan kualitas pelayanan kepada warga dari kekurangan dan keterbatasan terhadap air minum/air bersih. Permasalahan utama puluhan HIPPAM yang telah terbentuk di kabupaten Sidoarjo adalah, kurangnya kesadaran masyarakat dalam memanfaatkan air bersih yang telah disediakan oleh pemerintah daerah, kurang mampunya masyarakat berpenghasilan rendah dalam menanggung biaya pemasangan sambungan rumah (SR) serta kurang terampilnya pengurus HIPPAM dalam mengelola administrasi organisasi. Program PKM Himpunan Penduduk Pengguna Air Minum (HIPPAM) Desa Balongdowo dan Desa Putat Kecamatan Tanggulangin, Sidoarjo, Jawa Timur menawarkan solusi yang diharapkan dapat dilaksanakan oleh mitra kegiatan, yaitu warga desa Balongdowo dan desa Putat. Adapun metode pelaksanaannya adalah: pertama memberikan penyuluhan tentang pentingnya pemanfaatan air bersih untuk kehidupan sehari- hari, kedua memberikan sebuah metode penjernihan air dan ketiga dengan memberikan pelatihan manajemen pengelolaan HIPPAM sebagaimana layaknya sebuah lembaga yang dapat memberi keuntungan dan masukan bagi kas desa. Program ini juga bertujuan membantu masyarakat berpenghasilan rendah untuk mendapatkan sambungan rumah dari sumber air HIPPAM, serta melaksanakan pemantauan terhadap air HIPPAM desa Balongdowo dan desa Putat yang berasal dari sumur artesis, baik dalam segi kualitas maupun kuantitasnya. Dari program ini juga diharapkan pengurus dapat mengelola organisasi HIPPAM dengan baik dan profesional.
\end{abstract}

Kata kunci: HIPPAM, desa Balongdowo, desa Putat, sumur artesis, sambungan rumah

\section{PENDAHULUAN}

\section{Analisis Situasi}

Sidoarjo merupakan Kabupaten yang berada di Provinsi Jawa Timur, dan secara geografis terletak pada $7^{\circ} 20^{\prime}-7^{\circ} 34^{\prime}$ Lintang selatan dan $112^{\circ} 27^{\prime}$ - $112^{\circ} 52^{\prime}$ Bujur Timur. Kabupaten Sidoarjo terdiri atas 18 kecamatan, 322 desa dan 31 kelurahan. Adapun luas wilayahnya adalah 71.424,25 Ha. Berdasarkan data Kabupaten Sidoarjo dalam Angka tahun 2016, jumlah penduduk kota ini adalah sebesar 2.161.659 jiwa, dengan mata pencaharian penduduk di sektor pertanian, industri dan jasa. Peningkatan jumlah penduduk ini disebabkan karena arus urbanisasi, seiring dengan meningkatnya pembangunan di bidang perumahan, industri dan perdagangan.

Penyediaan air bersih untuk masyarakat mempunyai peranan yang sangat penting dalam meningkatkan kesehatan lingkungan atau masyarakat, yakni mempunyai peranan dalam menurunkan angka penderita penyakit khususnya yang berhubungan dengan air, dan berperan dalam meningkatkan standar atau kualitas hidup masyarakat. Sampai saat ini penyediaan air bersih untuk masyarakat di Indonesia masih dihadapkan pada beberapa permasalahan yang cukup kompleks dan sampai saat ini masih belum dapat diatasi sepenuhnya.

Permasalahan sumber daya air juga terjadi di wilayah Kabupaten Sidoarjo. Untuk itu pemerintah berupaya membentuk komunitas yaitu Himpunan Penduduk Pengguna Air Minum (HIPPAM) di mana sumber airnya adalah sumur artesis yang dibor dengan kedalaman lebih dari 100 meter. Dari sumur artesis diharapkan air yang keluar lebih bagus kualitas dan kuantitasnya dibandingkan dengan sumur biasa dengan kedalaman 5-6 meter Di antara sekitar 40 (empat puluh) HIPPAM yang ada di kabupaten Sidoarjo, ada dua HIPPAM yang menjadi mitra dalam kegiatan PKM ini, yaitu HIPPAM desa Balongdowo di kecamatan Candi. dan HIPPAM desa Putat di kecamatan Tanggulangin. 
Tabel 1.1 Permasalahan kedua mitra PKM

\begin{tabular}{ll}
\hline \multicolumn{1}{c}{$\begin{array}{c}\text { Permasalahan Mitra 1 } \\
\text { (HIPPAM Desa Balongdowo) }\end{array}$} & \multicolumn{1}{c}{$\begin{array}{c}\text { Permasalahan Mitra 2 } \\
\text { (HIPPAM Desa Putat) }\end{array}$} \\
\hline $\begin{array}{l}\text { 1. Jumlah pelanggan sedikit, disebabkan penduduk belum } \\
\text { mau memanfaatkan air bersih HIPPAM }\end{array}$ & $\begin{array}{l}\text { 1. Jumlah pelanggan banyak, tetapi belum terdata dengan } \\
\text { baik }\end{array}$ \\
\begin{tabular}{ll} 
2. Kualitas air terkadang keruh & 2. Sifat kesadahan air dan kandungan khlorida di atas nilai \\
3. Banyak warga yang keberatan terhadap biaya & standar \\
sambungan rumah karena permasalahan ekonomi & 3. Manajemen HIPPAM sudah terorganisasi dengan \\
4. Manajemen HIPPAM dikelola secara kekeluargaan & baik, tetapi ada pengurus yang belum terampil dalam \\
5. Tidak ada gaji tetap bagi petugas atau pengelola & menggunakan komputer \\
HIPPAM & 4. Kualitas sumber daya manusia masih perlu diperbaiki \\
\hline
\end{tabular}
\end{tabular}

Sumber: Kedua mitra PKM

Tabel 2.1 Solusi dan target kegiatan PKM

\begin{tabular}{|c|c|c|}
\hline Permasalahan & $\begin{array}{c}\text { Permasalahan Mitra } 1 \\
\text { (HIPPAM Desa Balongdowo) }\end{array}$ & $\begin{array}{l}\text { Permasalahan Mitra } 2 \\
\text { (HIPPAM Desa Putat) }\end{array}$ \\
\hline Harga tiap m3 & Rp. 1000 & Rp. 1500 \\
\hline Solusi: & $\begin{array}{l}\text { Secara bertahap harga dinaikkan agar } \\
\text { income bertambah }\end{array}$ & $\begin{array}{c}\text { Secara bertahap harga dinaikkan agar income } \\
\text { bertambah }\end{array}$ \\
\hline Target: & Harga menjadi Rp. 1250 & Harga menjadi Rp. 1750 \\
\hline Harga pasang SR & $\begin{array}{l}\text { Rp. 500.000, (Banyak warga yang keberatan } \\
\text { terhadap biaya sambungan rumah) }\end{array}$ & Rp. 700.000 \\
\hline Solusi: & $\begin{array}{c}\text { Ada subsidi silang dari warga yang mampu } \\
\text { terhadap warga tidak mampu }\end{array}$ & $\begin{array}{c}\text { Ada subsidi silang dari warga yang mampu } \\
\text { terhadap warga tidak mampu }\end{array}$ \\
\hline Uji Lab & $\begin{array}{l}\text { Belum pernah dilakukan, kualitas air } \\
\text { terkadang agak keruh }\end{array}$ & Tingkat kesadahan dan khlorida tinggi \\
\hline Solusi: & Uji Lab dilakukan & Penanganan masalah kualitas air \\
\hline Target: & $\begin{array}{l}\text { Bantuan: Kualitas air diperbaiki dengan } \\
\text { penyaring air sederhana }\end{array}$ & $\begin{array}{l}\text { Air terbebas dari sifat sadah dan Khlorida } \\
\text { yang tinggi (Bantuan: metode penjernihan air) }\end{array}$ \\
\hline Kualitas SDM & 6 orang & 8 orang \\
\hline Solusi: & $\begin{array}{l}\text { SDM harus memiliki ketrampilan di bidang } \\
\text { teknis dan manajemen Semua pegawai } \\
\text { telah terampil di bidang teknis dan } \\
\text { manajemen }\end{array}$ & $\begin{array}{l}\text { SDM harus memiliki ketrampilan di bidang } \\
\text { teknis dan manajemen Semua pegawai telah } \\
\text { terampil di bidang teknis dan manajemen }\end{array}$ \\
\hline Sarana dan prasarana & Tidak memiliki komputer & Belum paham aplikasi komputer \\
\hline Solusi: & $\begin{array}{c}\text { Pemberian bantuan seperangkat komputer } \\
\text { dan printer untuk peningkatan kualitas } \\
\text { manajemen HIPPAM }\end{array}$ & $\begin{array}{c}\text { Pemberian bantuan seperangkat komputer dan } \\
\text { printer untuk peningkatan kualitas manajemen } \\
\text { HIPPAM }\end{array}$ \\
\hline Gaji pegawai & Tidak tetap & Minimal Rp 400.000/bulan \\
\hline Solusi: & Pegawai HIPPAM harus mendapat gaji tetap & Ada peningkatan gaji sesuai masa kerja \\
\hline Target: & Sistem penggajian tetap dan tepat waktu & Sistem penggajian tetap dan tepat waktu \\
\hline Saldo terakhir & Rp. 210.000 & Rp. 16.250 .000 \\
\hline Solusi: & $\begin{array}{c}\text { Saldo harus ditingkatkan supaya kegiatan } \\
\text { HIPPAM berjalan lancar }\end{array}$ & Saldo bisa lebih ditingkatkan \\
\hline Target: & Saldo minimal: Rp. 1.000 .000 tiap bulan & $\begin{array}{l}\text { Sebagian saldo bisa dianggarkan untuk } \\
\text { meningkatkan kualitas SDM }\end{array}$ \\
\hline
\end{tabular}

Sumber: Hasil analisis 


\section{Permasalahan Mitra}

Permasalahan yang dihadapi HIPPAM desa Balongdowo adalah minimnya jumlah pelanggan, kualitas SDM pengelola HIPPAM yang kurang terampil, sarana dan prasarana yang belum memadai serta manajemen HIPPAM yang belum bagus. Dengan jumlah penduduk sekitar 3100 jiwa, diharapkan HIPPAM di desa Balongdowo bisa dikelola dengan lebih baik. Sedangkan HIPPAM "Tirto Barokah" desa Putat menunjukkan prestasi yang cukup menggembirakan. Pada tahun 2014, HIPPAM ini terpilih menjadi juara I tingkat Kabupaten Sidoarjo untuk pengelolaan HIPPAM terbaik dan pelanggan terbanyak. Dengan jumlah pelanggan lebih dari 300, HIPPAM ini berhasil meraup keuntungan cukup banyak untuk kepentingan perawatan sumur artesis, menggaji pegawai serta memberi "income" bagi kas desa.

Secara garis besar, permasalahan kedua mitra PKM dapat diringkas pada Tabel 1.1 dan 1.2.

\section{SOLUSI DAN TARGET LUARAN}

Solusi dan target yang bisa ditawarkan pada kegiatan PKM Himpunan Penduduk Pengguna Air Minum (HIPPAM) Desa Balongdowo dan Desa Putat Kecamatan Tanggulangin, Sidoarjo, Jawa Timur ditunjukkan pada tabel 2.1 berikut.

\section{METODE PELAKSANAAN}

Metode yang akan diterapkan oleh Pengusul pada kegiatan PKM Himpunan Penduduk Pengguna Air Minum (HIPPAM) Desa Balongdowo dan Desa Putat Kecamatan Tanggulangin, Sidoarjo, Jawa Timur, yaitu:

1. Penyuluhan kepada warga akan manfaat air bersih

2. Pemberian bantuan sambungan rumah bagi warga tak mampu

3. Memberikan pelatihan manajemen bagi pengurus HIPPAM

4. Membantu menghubungkan HIPPAM dengan Pemda setempat yang berwenang, dalam hal ini Dinas PU Perumahan dan Permukiman untuk mendapatkan bantuan yang dibutuhkan.

\section{Penyuluhan kepada Warga akan Manfaat Air Bersih}

Gambar 3.1 memperlihatkan proses penyuluhan dan pemberian bantuan pada pengurus HIPPAM desa Balongdowo, sedangkan gambar 3.2 pada desa Putat.

\section{Pemberian Bantuan Sambungan Rumah Bagi Warga Tak Mampu}

Seperangkat alat Sambungan ke Rumah atau SR yang terdiri dari meter pencatat air, kran pipa, da penutup meteran, diberikan untuk warga tak mampu di desa Putat.

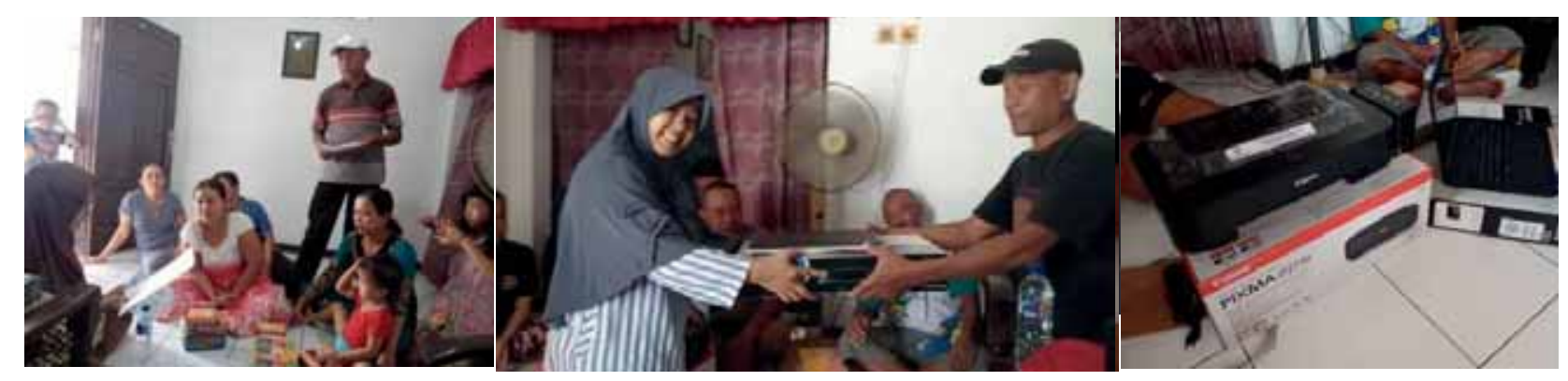

Gambar 3.1 Penyuluhan dan pemberian bantuan pada HIPPAM Balongdowo

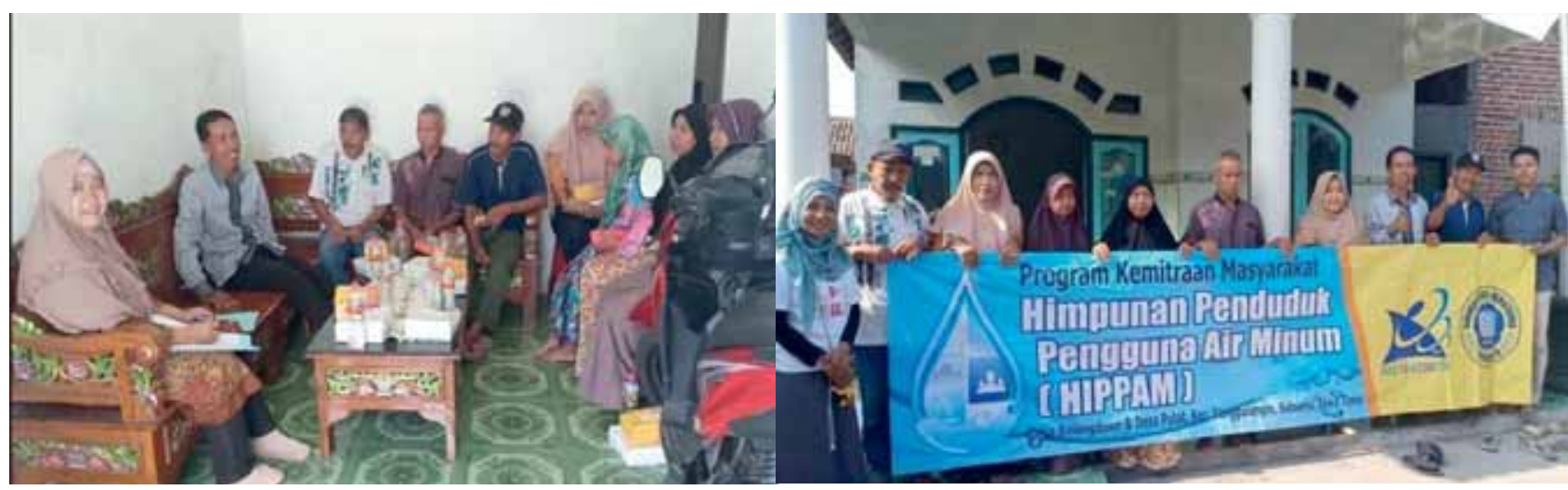

Gambar 3.2 Penyuluhan manajemen HIPPAM di Desa Putat 
Pemasangan berdasarkan skema seperti ditunjukkan pada gambar 3.3 dan gambar 3.4.

\section{Pelatihan Manajemen HIPPAM Bagi Pengurus}

Pengelolaan organisasi HIPPAM selayaknya dilakukan secara profesional. Program PKM ini akan memberi pelatihan penggunaan komputer bagi pengurus HIPPAM, antara lain program Microsoft Office (MS Word dan MS Excel). Pengurus

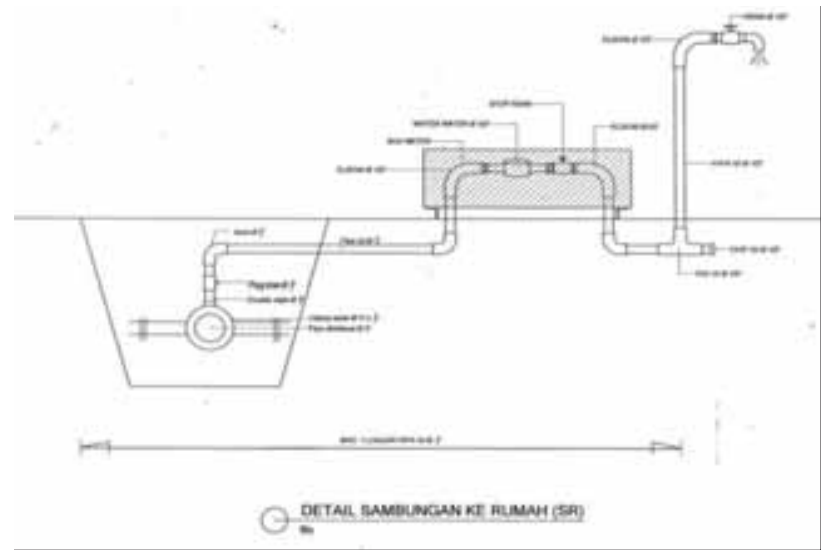

Gambar 3.3 Bagan Sambungan ke Rumah juga akan mendapatkan bantuan seperangkat komputer dan printer untuk menunjang kegiatan pengelolaan HIPPAM.

Pelatihan Manajemen HIPPAM pada dasarnya dilaksanakan untuk meningkatkan kemampuan dan penguatan manajemen pengelola air bersih berbasis teknologi. Harapannya adalah meningkatkan tata kelola usaha air bersih (HIPPAM) pada dua mitra PKM. Materi pelatihan antara lain mencakup:

- Analisa biaya modal, Struktur modal dan penganggaran modal

- Ketrampilan dalam pengadministrasian dan pengelolaan organisasi

- Pencatatan dan pelaporan, penataan dan penguatan organisasi

- Pengembangan strategi komunikasi organisasi, manfaat dan tujuan kelayakan usaha dan aspek aspek dalam analisis kelayakan usaha

Gambar 3.2, 3.3 dan 3.4 menunjukkan contoh model pencatatan tagihan pelanggan HIPPAM pada bulan tertentu, struk pembayaran, dan contoh kartu pelanggan.

4. Membantu menghubungkan HIPPAM dengan Pemda setempat yang berwenang, dalam hal ini Dinas PU Perumahan dan Permukiman untuk mendapatkan bantuan yang dibutuhkan.

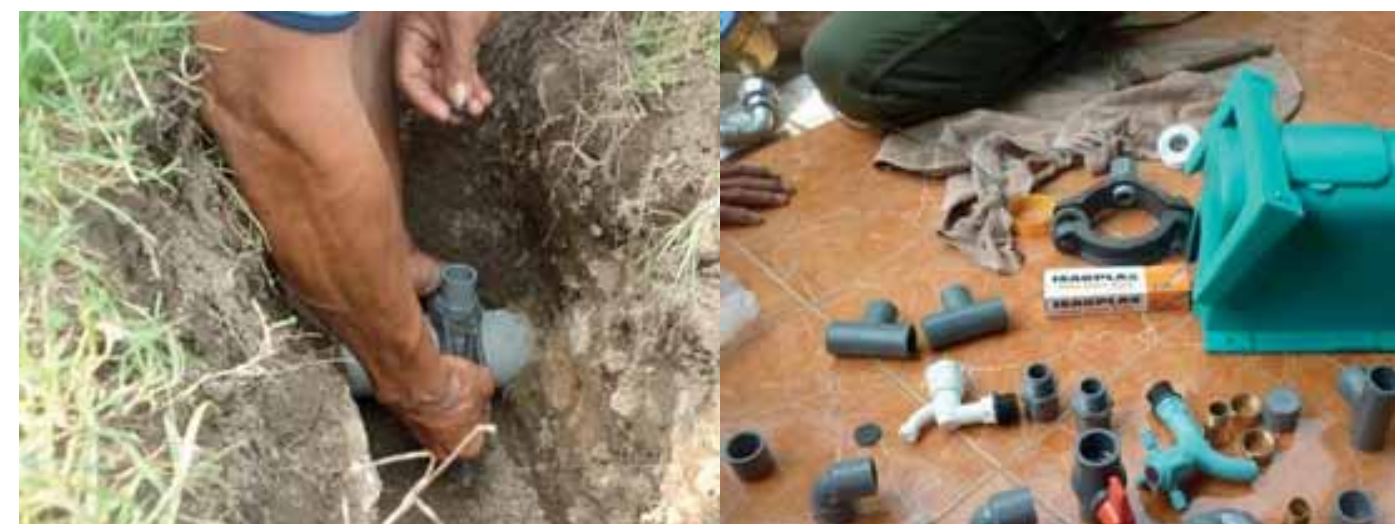

Gambar 3.4 Proses pemasangan sambungan rumah (1)

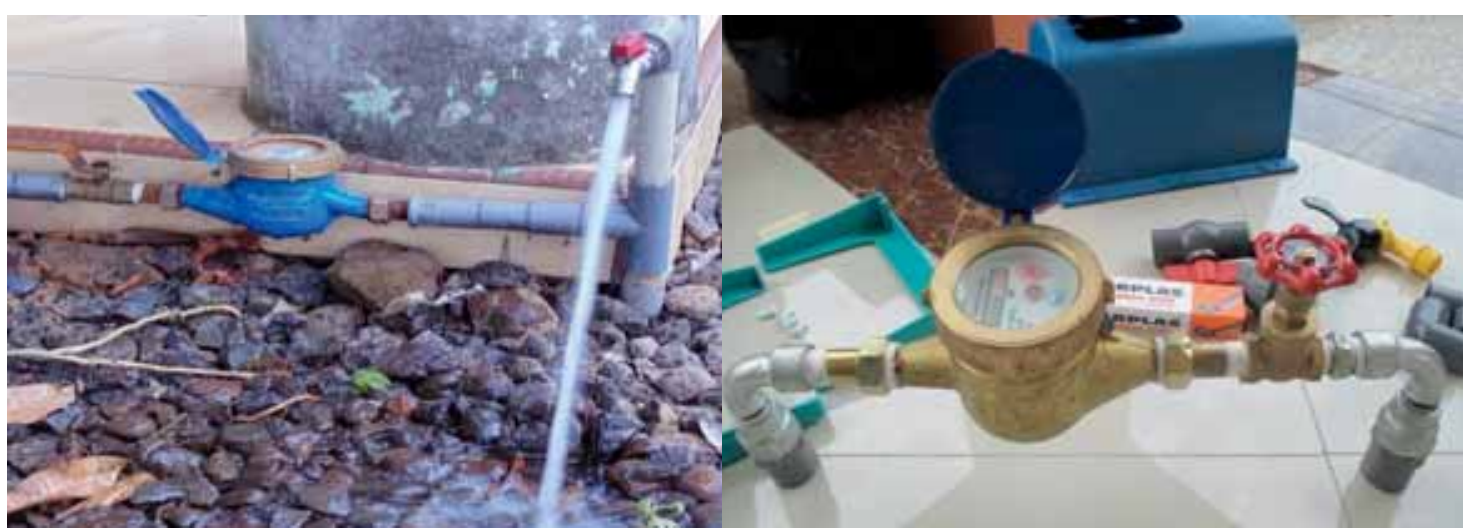

Gambar 3.4 Proses pemasangan sambungan rumah (2) 


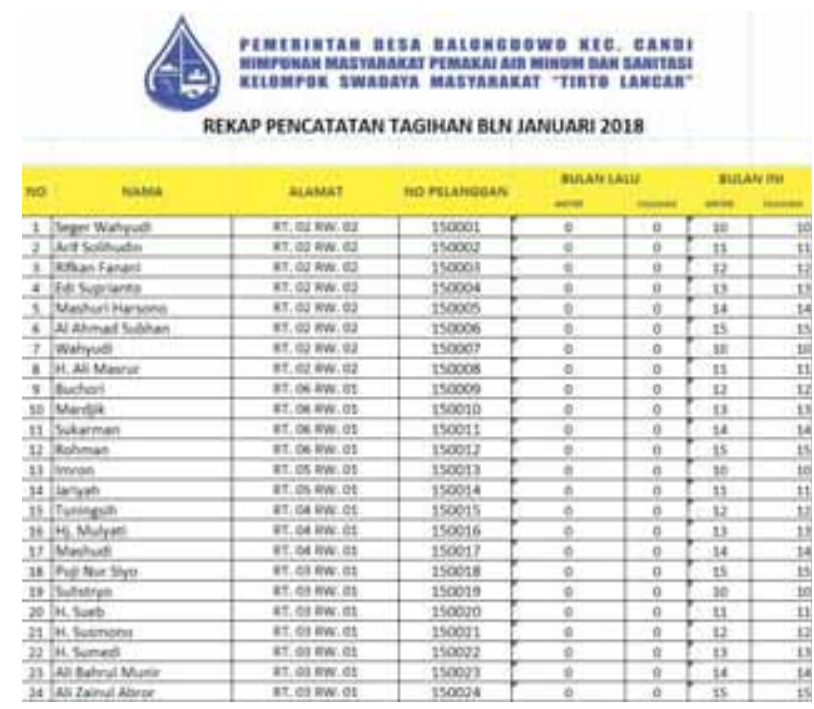

Gambar 3.6 Rekapitulasi data pelanggan HIPPAM

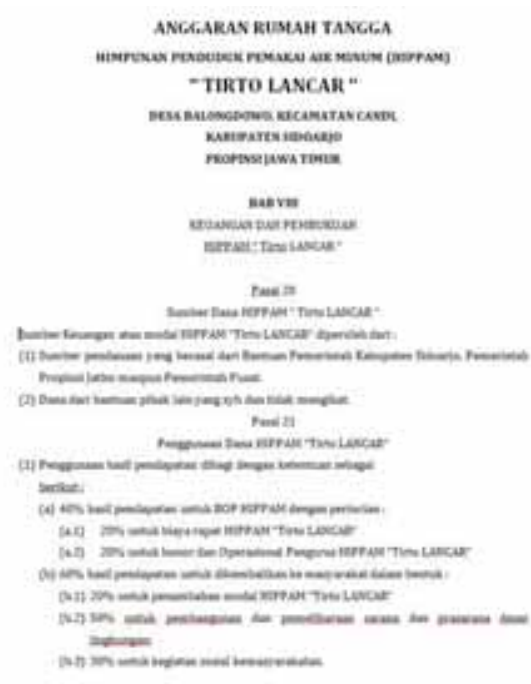

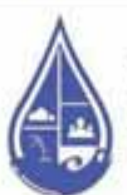

PEMERINTAH DESA BALOHGDOWO KEC. CAMDI HIMPUKAN MASYARAKAT PEMAKCAI AIR MIKUM DAN SANITASI KELOMPOK SWADAYA MASYARAKAT "TIRTO LAMCAB"

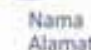

Alams

No. Pelanggar

\begin{tabular}{|c|c|c|c|c|}
\hline \multicolumn{2}{|c|}{ Angka Stand Dalain Metet } & \multirow{2}{*}{ Perrakiaan Bulan ini (m) } & \multirow{2}{*}{ Harga (m) } & \multirow{2}{*}{ Toghthan Bulan in } \\
\hline Bulan Lalu & Bulan in & & & \\
\hline & & & & 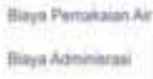 \\
\hline \multicolumn{4}{|c|}{ Jumlah Tagihan } & \\
\hline
\end{tabular}

penurue

Batongtowo, 2015

Pestugas

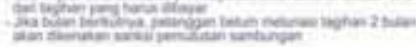

Gambar 3.7 Struk pembayaran pelanggan HIPPAM

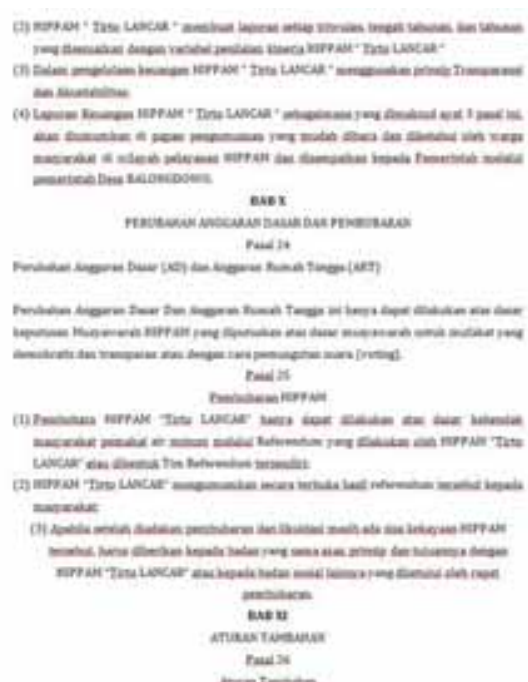

Gambar 3.9 Anggaran Rumah Tangga HIPPAM Balongdowo
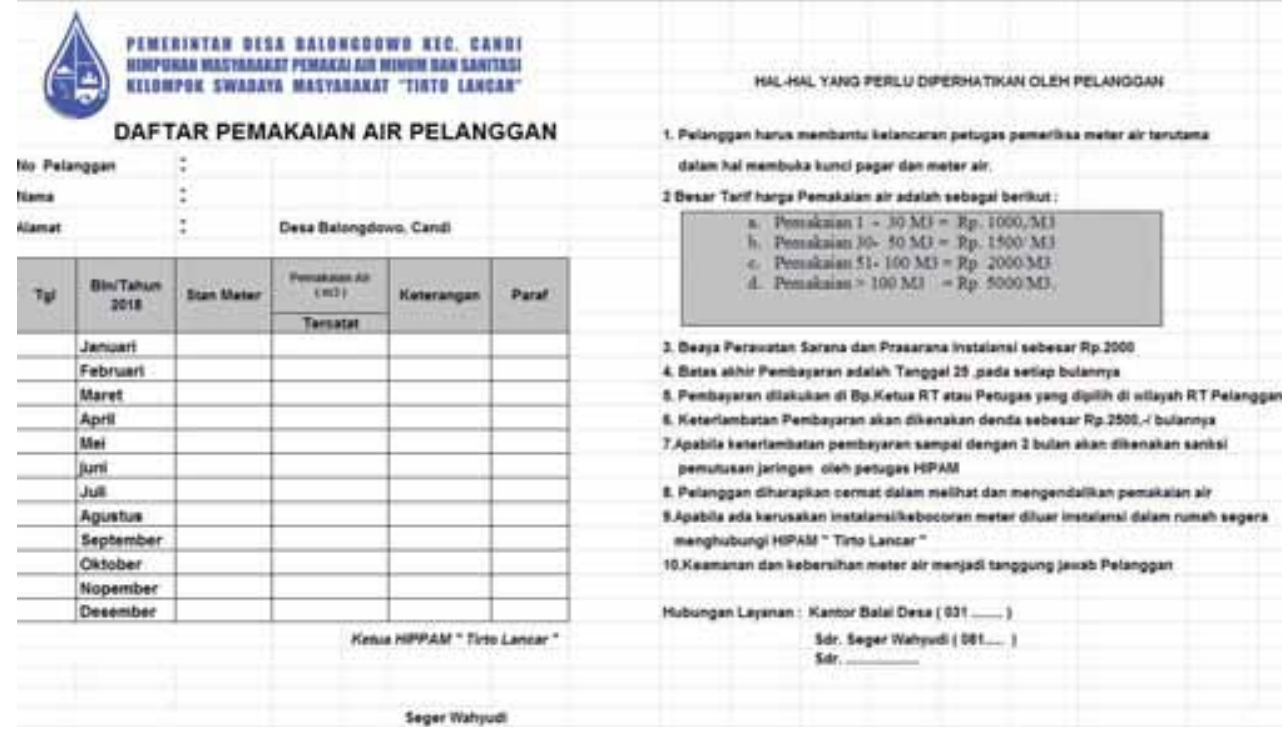

Gambar 3.8 Kartu pelanggan HIPPAM 
Bentuk bantuan yang diberikan untuk membantu menghubungkan mitra dengan instansi terkait adalah dengan pembuatan Anggaran Dasar (AD) dan Anggaran Rumah Tangga (ART), seperti pada gambar 3.7.

\section{EVALUASI PELAKSANAAN PKM}

Sebagai tindak lanjut terhadap program PKM Himpunan Penduduk Pengguna Air Minum (HIPPAM) Desa Balongdowo dan Desa Putat Kecamatan Tanggulangin, Sidoarjo, Jawa Timur, Tim Pengusul akan melakukan monitoring dan evaluasi. Kegiatan ini dimaksudkan untuk memantau keberhasilan dan keberlanjutan program.

Dalam sebuah kegiatan pelatihan, monitoring/pemantauan sangat penting untuk dilakukan. Monitoring dapat digunakan untuk mengukur proses kegiatan pelatihan, juga dapat dijadikan instrumen untuk meminimalisasi kemungkinan terjadinya kesalahan dalam pelaksanaan proses kegiatan pelatihan.

Indikator keberhasilan kegiatan PKM Pelatihan Pengelolaan Manajemen HIPPAM adalah ditunjukkan dengan terlaksananya solusi dan terpenuhinya target yang telah ditetapkan. Untuk itu tim Pengusul akan menjadwalkan kunjungan secara berkala pada dua mitra PKM. Kunjungan ini dimaksudkan selain untuk memantau keberhasilan program, juga untuk mempererat tali silaturahim antara tim pengusul, pengurus HIPPAM, dan warga desa mitra.

\section{REFERENSI}

Jurnal Sipil Statik Vol.1 No.6, Mei 2013 (444-451) ISSN: 2337-6732 444

Pengembangan Sistim Pelayanan Air Bersih Ridwan Naway F. Halim, M. I. Jasin, L. Kawet Fakultas Teknik, Jurusan Teknik Sipil, Universitas Sam Ratulangi. email: Ridwannaway@ymail.com

Linsley, Ray K, dan Yoseph B. Franzini. 1996. Teknik Sumber

Daya Air. Jilid I. Jakarta: Erlangga, Pedoman/Petunjuk

Teknik Dan Manual Bagian 6: Air Minum Perkotaan, Kimpraswil

Ruliasih Marsidi, Jurnal Teknologi Lingkungan, Vol.2, No. 1, Januari $2001: 1-10$

Swesty Ari Donya, Ery Suhartanto, Very Dermawan, Jurnal Teknik Pengairan Universitas Brawijaya Malang, Studi Perencanaan Sistem Penyediaan Air Bersih Di Desa Serang Kecamatan Panggungrejo Kabupaten Blitar

Yurman, Pascasarjana Pengelolaan Sumberdaya Alam dan Lingkungan, Fakultas Pertanian Universitas Bengkulu, 2014 Pengaruh Kadar Klorida Pada Air Sumur Gali 